\title{
Research on the Talents Education Scheme Based on Integration of Science and Education for Information and Communication Engineering
}

\author{
Zhendong Yin, Zhilu Wu, Dasen Li, Yaqin Zhao, and Jinlong Liu
}

\begin{abstract}
Information and Communication Engineering is the forefront of science and technology competition among major countries in the world, which is characterized by rapid updating of knowledge system, extensive cross-cutting of scientific research directions and high requirements on the innovation ability of talents. This paper puts forward the mode of cultivating graduate innovative talents in information and communication engineering subject, which combines morality and talent, science and education. Guided by the spirit of scientists, to carry out ideological and political education in an all-round and multidimensional way, the training mode aims to comprehensively enhance the motivation of graduate students and aims to enhance the ideal and faith of serving and developing a powerful country through science and innovation, with high-level scientific research projects and innovative achievements as the guidance, the integration of science and education and multiple measures to cultivate graduate students' scientific research innovation practical ability. The practice shows that the moral education effect of the talent training mode proposed in this paper is remarkable, which greatly improves the motivation of study and enthusiasm for innovation of postgraduates and strengthens the ideal and faith of a strong country in science and technology. Moreover, the innovation ability of the graduate students has been significantly improved, and the graduate students have made great progress in systematic thinking, creative thinking and practical ability. Besides, they have made more high-level innovation achievements.
\end{abstract}

Index Terms-Integration of science and education, information and communication engineering, education scheme, graduate innovative talents.

\section{INTRODUCTION}

The cultivation of graduate talents should adhere to the purpose of establishing morality and cultivating people, and the fundamental task is to cultivate high-quality builders and successors of the socialist cause with all-round development of morality, intelligence, physical education, art, and labor [1]. The discipline of information and communication engineering has the characteristics of rapid update of knowledge system, wide range of scientific research directions, rapid development of frontier subjects, and high requirements for innovation capabilities [2]. It is the frontier of competition in the scientific and technological fields of major countries in the contemporary world. It is the strategic,

Manuscript received October 10, 2021; revised November 16, 2021.

The authors are with Harbin Institute of Technology, Harbin, China (corresponding author: Zhilu Wu; e-mail: yinzhendong@hit.edu.cn, wuzhilu@hit.edu.cn, sen09024@hit.edu.cn, zhaoyaqin@hit.edu.cn, yq20@hit.edu.cn). basic and leading discipline which supports economic and social development and ensures national security. It is also the discipline that are most impacted by the current drastic changes in the external situation facing our country and it exists with many rote memorization technologies. In response to the question of how to cultivate leading innovative talents who are mindful of the motherland and are determined to innovate, capable of meeting the major national needs and leading the development of the future industry, this achievement puts forward "the simultaneous development of morality and talent, the integration of science and education, and guided by the cultivation of the spirit of scientists, facing the major needs of the country, it aims to consolidate the theoretical foundation [3], cultivate the ability to innovate [4], and strengthen the practice of scientific research [5]. Take the academician Liu Yongtan, the winner of the national science and technology award, as an example, and take patriotism, innovation, truth-seeking, dedication, collaboration, and educating scientists and disciplines Innovative talents need to have systemic thinking, creative thinking, practical ability, teamwork ability, knowledge accumulation five aspects of quality training as the goal [6], with high-level innovation results as the traction, the electronic information discipline innovative talent training mode is constructed [7]. The talent training mode includes educational concepts, training objectives, training programs, training process, teaching mode, and talent training quality assurance system [8].

\section{BACKGROUND}

China's electronic information industry is faced with the complex and severe external situation of frontier technology blockade and cutting-edge products embargo, and it is in urgent need of cultivating the postgraduate talents who are open-minded and innovative [9], and can overcome the "stuck" technology to meet the major needs of the country [10]. The proposed training mode makes it clear that the training of postgraduate talents in electronic information disciplines should emphasize both morality and talent -focusing on cultivating leading innovative talents in the field of electronic information with noble moral character [11], scientist spirit and scientific research innovation ability [12].

1) Under the current situation, the training of talents in the electronic information industry should follow the principle of "self-reliance, hard work, and independent innovation", requiring talents in this discipline to have a strong "patriotism and dream of making the country 
stronger." Under the traditional talent training mode, ideological and political education is not centralized, and the integration of subject knowledge system is not strong, and it is impossible to form a joint force for ideological and political education. The proposed training mode clarifies that the goal of ideological and political education in electronic information disciplines is to cultivate the "scientist spirit", and to promote and explain the patriotic, innovative, realistic, dedication, collaborative, and educating scientist spirit in the curriculum ideological and political teaching and various training links.

2) The training plan and training process under the traditional training mode of postgraduate talents in the discipline are not clear about the connotation of the training of scientific research innovation ability, which cannot meet the training goals and demands of innovative talents in the discipline to "solve the major national needs and break through the bottleneck technology". The proposed training mode clarifies the five qualities that should be paid attention to in the education of innovative talents in electronic information disciplines, and emphasizes on cultivating students' systematic thinking, creative thinking, practical ability, teamwork ability and knowledge accumulation in the process of training, so as to enhance the ability of scientific research and innovation.

3) Under the traditional talent training mode, teaching activities and scientific research platforms are not obvious for the cultivation of students' innovative ability and innovation achievements, and lack of open and flexible science and education integration, independent learning, team collaboration technology innovation environment, atmosphere and practice platform. Besides, students' scientific research and innovation practice and teamwork ability needs to be strengthened, and there is insufficient experience in building high-level innovation results. Submit your manuscript electronically for review.

\section{EDUCATIONAL SCHEME}

Optimize talent training objectives, training programs, training processes and curriculum systems [10]. Taking "based on aerospace, serving national defense, facing major national needs, leading innovative talents with scientist spirit and high-level scientific research and innovation capabilities" as the training goal, the main body of "curriculum teaching-scientific research-subject competition-social practice" is constructed. The four links run through the whole process of ethics and talents, and a talent training mode that integrates science and education (Figure 1). Relying on more than 200 disciplines of basic research in seven major scientific research directions and frontier research projects in the fields of defense and aerospace to optimize master and doctor training programs and curriculum systems: 28 professional core courses, 37 professional courses, and 8 frontier topic courses are opened, 12 innovative practical courses, and 161 (322 hours) exploratory experimental projects based on scientific research results.

With the goal of cultivating the spirit of scientists, we implement the ideological and political education mode of the four-in-one science and education integration of "curriculum ideological and political + scientific research ideological and political + competitive ideological and political + practical ideological and political", which forms a joint force of discipline ideological and political education.

In the construction of ideological and political elements of curriculum teaching, combining the history and practice of discipline development, Harbin Institute of Technology has 800 heroes, two bombs and one star, and the traditional spirit of aerospace to promote and cultivate the spirit of contemporary Chinese scientists, as shown in Figure 2.

In the ideological and political scientific research and competition links, it puts forward the perceptual education method of "integrating the spirit of scientists in scientific research and innovation practice", insists on selecting topics based on aerospace, serving national defense, facing the frontiers of science and technology in the world, facing major national needs and choking technology. Taking the deeds of the academician Liu Yongtan of the discipline as an example, we personally lead, seek truth and strict requirements, encourage students to achieve high-level innovation results with the spirit of being a scientist who is brave to explore, innovate, be good at collaboration, and willing to contribute, and establish science to serve the country and innovate the ideals and beliefs of a powerful country.

In the ideological and political social practice link, various forms and activities are adopted to carry out publicity and education, including academician Liu Yongtan's advanced deeds report and lectures, Harbin Institute of Technology's 800 heroic spirit lectures, regular party lectures and international lectures, red education base research, and aerospace defense research institutes. Various forms such as strengthening students' patriotic belief, innovative thinking, realistic style, dedication consciousness, collaborative concept, and cultivating feelings of students.

Construct and implement the five-in-one innovation ability training mechanism of "learning content + learning form + practice platform + team guidance + achievement condensing".

1) Learning content: Reform the teaching content and teaching materials, and integrate the cutting-edge high-level research results, innovative methodology education and academic moral education into the curriculum teaching and teaching materials construction.

2) Learning form: Propose and practice a new teaching model of "self-selection of topics, interactive research, and team-based learning for scientific and technological innovation (STIPBL)", integrating the learning process into the exploration and practice of cutting-edge scientific issues.

3) Practice platform: Relying on the achievements of discipline construction, a multi-level high-level innovation practice environment and platform has been constructed, and an appointment-based scientific research practice resource sharing mechanism of "independent innovation, open platform, and equipment sharing" has been implemented for all graduate students. 


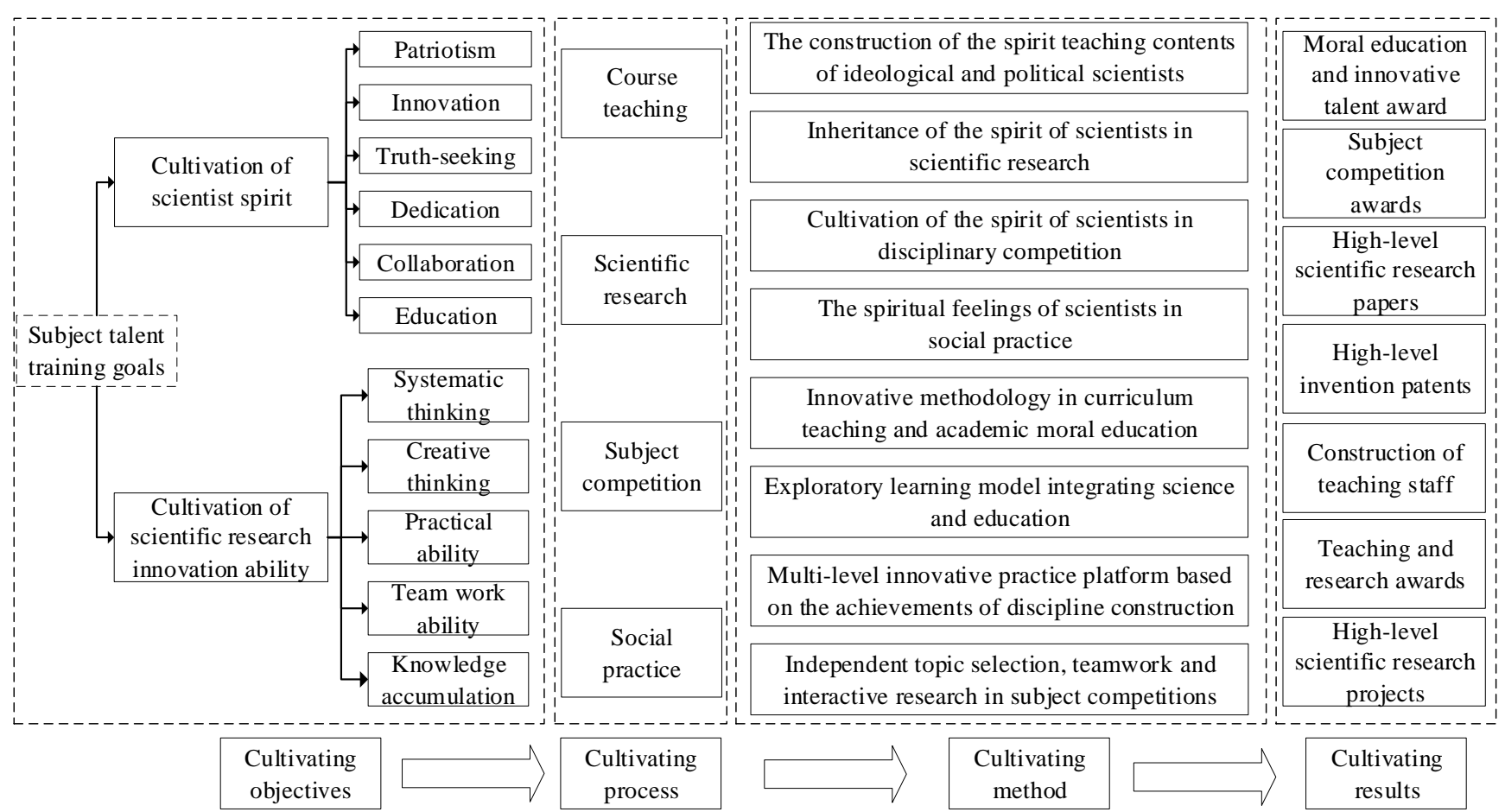

Fig. 1. Education scheme topology of morality, ability and scientific knowledge fused model.

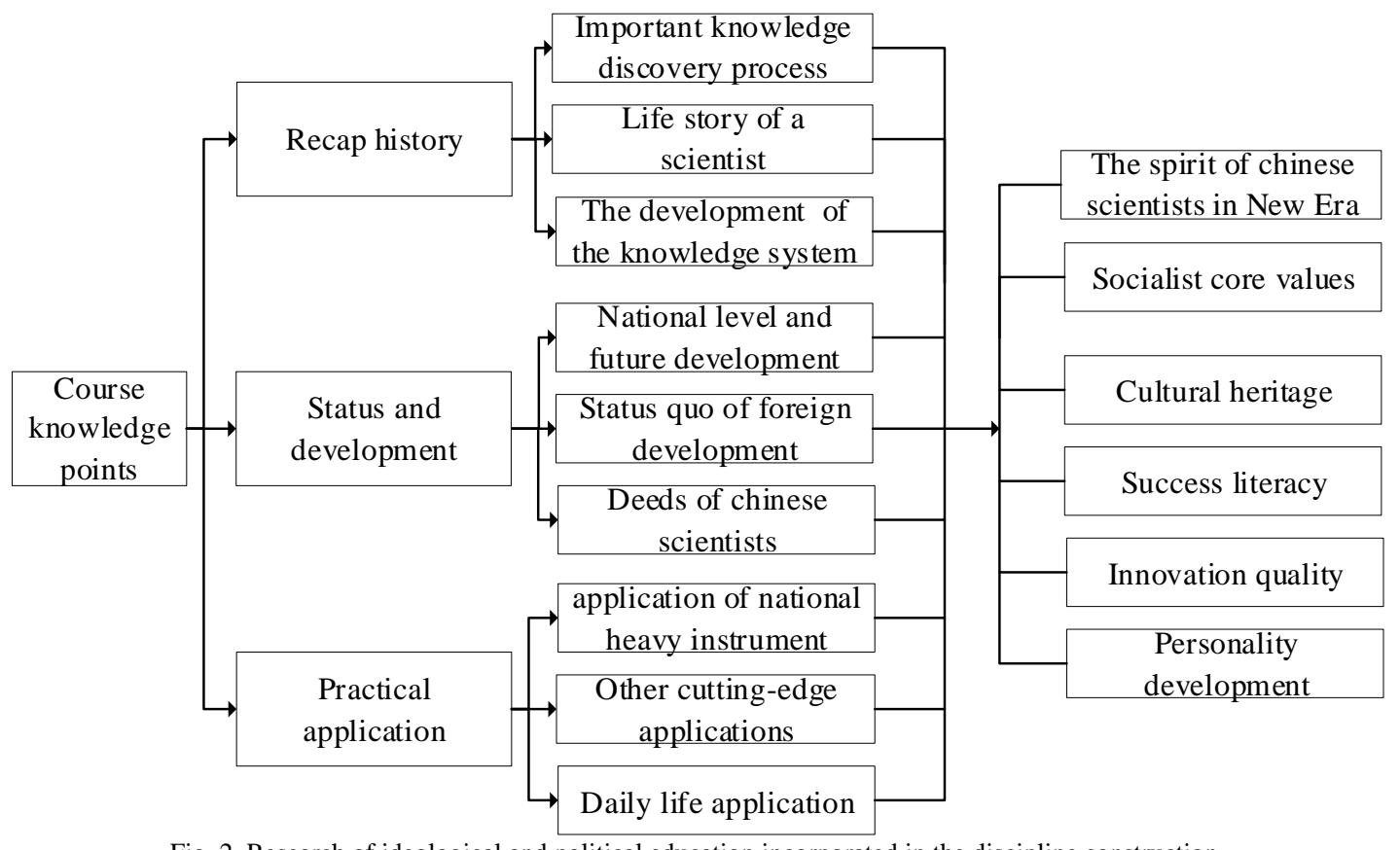

Fig. 2. Research of ideological and political education incorporated in the discipline construction.

4) Team guidance: Establish a multi-directional cross-innovation tutor group, change "one-to-one" guidance to "many-to-one" guidance, provide comprehensive guidance for students' scientific research, discipline competitions, innovation and entrepreneurship and other social practices, and improve graduate students' application to major national needs Multi-directional cross-knowledge ability to solve technical problems of "stuck neck".

5) Achievement condensing: Create a condensing mechanism for innovation achievements. The "many-to-one" tutor team will focus on the characteristics of graduate students' projects, and carry out corresponding innovation achievements condensed guidance for high-level scientific research papers, invention patents, and innovation and entrepreneurship discipline competitions, so as to improve the high level of graduate students. Condensation and construction experience of innovation and entrepreneurial achievements.

Establish and improve the personnel training quality assurance mechanism. We will implement programs to improve teachers' teaching ability, train young teachers, and cultivate teaching achievements, encourage the training of leading innovative talents with both integrity and ability, and take teacher ethics and talent training quality as the core evaluation indexes for teachers' evaluation and promotion. Implement the student evaluation mechanism that emphasizes both morality and talent, and strengthen the moral education performance with the scientist spirit as the 
core and the scientific research innovation achievement as the mark in the scholarship evaluation, talent evaluation and the examination of college entrance examination at all levels. The above-mentioned guarantee mechanism has been continuously improved, and a series of institutional documents have been formed and resolutely implemented. With the system as the guide, fully mobilize teachers and students in teaching and learning in the integration of science and education practice of the spirit of scientists and scientific research innovation ability of the enthusiasm of training, for the implementation of the implementation of the innovative personnel with both political integrity and ability to provide high-quality teachers and development environment.

\section{TEACHING REFORM}

\section{A. Moral Education}

The moral education has achieved remarkable results, and the students' ideological level has been improved. After graduation, they have devoted themselves to aerospace and national defense industries and national pillar enterprises. The participation rate of students in ideological and political education reached $100 \%$ in each training process, and many excellent talents with both political and moral integrity were cultivated, including the Star of Chinese College Students, the Top Ten Young Volunteers of Heilongjiang Province, and the Outstanding Student Award of Baosteel. In recent years, the students have been awarded 16 national, provincial and ministerial moral education awards, including 2 national and 14 provincial and ministerial moral education awards, and 81 graduate students have won national scholarships. In recent years, an average of 62.1 percent of master's and doctoral graduates have devoted themselves to the aerospace and defense industry or entered pillar enterprises of the national information industry such as Huawei and ZTE. A large number of distinguished alumni have devoted themselves to serving the country through science, and have made outstanding contributions to the development of China's space, national defense and information industries by developing a large number of "stuck" technologies, including manned space flight, lunar exploration project, 5G, new system radar and domestic large aircraft.

\section{B. Professional Education}

The achievements of professional education are remarkable, the postgraduate research experience is rich, and the innovation ability is enhanced. Students' innovation ability and achievements have been greatly improved. The participation rate of science and technology innovation projects and innovation practice courses is $100 \%$. The selection rate of graduate theses based on cutting-edge basic research and high-level scientific research projects in aerospace and national defense fields is over 95\%. In high-level discipline competitions, our graduate students have won 50 awards, including 13 at national level and 37 at provincial and ministerial level. In 2018 China Graduate Electronic Design Competition sponsored by the Ministry of Education, our graduate team won the first prize at national level. The results radiated to undergraduate training. Team members guided undergraduate students to win 63 prizes in discipline innovation competitions, 19 of which were national level. As the chief engineer and core member, undergraduate students of our college were responsible for the development of "Lilac 2", the first micro/nano satellite independently developed and successfully launched by the student team in China. In the National University Bionetworking Design Competition, our student team won the only special prize (TI Cup) in 2014 and 2017. In recent years, the graduate students have published more than 500 SCI retrieval papers, including 10 ESI highly cited papers, and more than 500 invention patents.

\section{Disciplinary Influence}

Social reputation and disciplinary influence have been significantly enhanced. Academician Liu Yongtan of our discipline won the 2018 National Highest Science and Technology Award, which is the first and only scientist in Our province to receive this award. At present, academician Liu Yongtan's advanced deeds report group has made nearly one hundred lectures for more than ten thousand listeners. The lecture journey of nearly 8000 kilometers has aroused strong response among teachers and students of more than one hundred universities in China. Beijing, Harbin, Daqing, Mudanjiang, Weihai, Shenzhen, etc. The delegation traveled across more than half of China to speak well of the spirit of Chinese scientists in the new era. Academician Liu yongtan's advanced deeds and patriotic feelings have infected the striving people from all over the country and become a spiritual force to encourage them to move forward. In response to the National "Belt and Road" initiative, the discipline has hosted four China-Uzbekistan Science and Technology forums and more than 10 high-level international conferences, and established four IEEE sub-associations, which are famous international academic organizations. The results of the fourth round of discipline evaluation by the Ministry of Education were excellent (joint seventh).

\section{Research Results}

The research results were well received, and the practical experience was popularized. The team has published 37 teaching research papers, among which 4 CSSCI source journal papers have been cited for 46 times. The team has been cited and positively evaluated by scholars from 17 double-first-class universities, including Renmin University of China, Zhejiang University, Beijing Normal University and so on. He has made a special report in the national Graduate School engineering Graduate Education Seminar, national Defense Science and Technology Industry youth Forum and other important teaching conferences. His thesis achievements have won four national and provincial excellent paper achievement awards. Beijing University of Posts and Telecommunications, Dalian University of Technology and other 8 universities on results gave a high evaluation, feel that the results of education ideas and their subject on talent training pattern and computer science, electronic science and technology and other brother this teaching and personnel training and research has a strong role in promoting, and introduces the results of the teaching 
methods and experience in the talent cultivation system.

\section{E. Construction of Teaching Staff}

The construction of teaching staff has achieved obvious results and teaching resources have been expanded rapidly. Team teachers have undertaken 38 national, provincial and university-level educational reform projects, and published 13 textbooks, including 7 national-level key books. Team teachers have won more than 30 teaching and research awards and honorary titles, such as National Science and Technology Progress Award, Innovation Education Award of China Higher Education Association, Science and Technology Progress Award of Heilongjiang Province, etc. Fifteen well-known overseas experts and scholars including Alexander Denisov, academician of The Ukrainian Academy of Sciences, were introduced, 12 high-level courses jointly built by international scholars and more than 10 teaching platforms and practice bases such as national engineering practice education center and collaborative innovation center were established.

\section{CONCLUSION}

To sum up, the cultivating model of innovative talents for postgraduates in the information and communication engineering disciplines proposed in this article is closely related to the cultivating goal of graduate students' learning motivation, ideals and beliefs, and the cultivation of scientific research and innovation capabilities. Innovate from the concepts of education, methods of education, learning process, training links, teaching content, etc., guided by the spirit of scientists and high-level innovations, and educate people through courses, research and education, practice education, and competition education. People and other links are integrated to establish the ideals and beliefs of postgraduates to serve the country scientifically and to make the country strong through innovation, and to cultivate five aspects of scientific research and innovation qualities of systematic thinking, creative thinking, practical ability, teamwork ability and knowledge accumulation. Teaching practice has proved that the moral education effect of the talent training model proposed in this article is significant, which can greatly enhance the motivation of graduate students and the belief in serving the country; at the same time, the professional education of this model has significant effects, the research and innovation ability of graduate students has been significantly enhanced, and more advanced achievements have been made. The achievement of level innovation is a postgraduate talent training model worthy of promotion.

\section{CONFLICT OF INTEREST}

The authors declare no conflict of interest.

\section{AUTHOR CONTRIBUTIONS}

Zhendong, Yin. designed, performed the research, and wrote the paper. Dasen, Li. Yaqin, Zhao. and Jinlong, Liu. collected the data and helped in editing the paper. Zhendong, Yin. and Zhilu, Wu. procured the funding.

\section{ACKNOWLEDGMENT}

This work was supported by National Natural Science Foundation of China (Grant Nos. 61871157) and General program of Chinese society of degree and graduate education (Grant Nos. 2020MSA409).

\section{REFERENCES}

[1] L. J. Liu et al., "Study and practice on talent cultivation for electronic information engineering and technology," Journal of Wuhan University (Natural Science Edition), 2012.

[2] J. F. Zang and Y. Q. Liu, "New engineering construction and development of electronic information specialty under the concept of Obe," Journal of Frontiers in Educational Research, vol. 1, no. 2, pp. 19-22, 2021

[3] J. Jing and Y. Y. Chen, "Research on the practice of talent cultivation based on the improvement of innovation ability - Taking electrical engineering automation technology as an example," Journal of Physics: Conference Series, vol. 1651, no. 1, 2020.

[4] G.-L. Wang et al., "Research on talent training model of interdisciplinary integration — Taking electronic information engineering specialty of Anhui Polytechnic University for example," Journal of Хinyu University, 2017.

[5] L. I. Jun, S.-S. Chai, and F. A. N. G. Yan, "An analysis of the way to cultivate outstanding talents of electronic information and communication engineering specialty in the future," DEStech Transactions on Social Science, Education and Human Science, 2020.

[6] Y.-F. Gao, Z.-L. Wang, and L. Zhang, "Exploration on talents training cultivation mode of electronic information and communication major," presented at 4th International Conference on Management Science, Education Technology, Arts, Social Science and Economics 2016, Atlantis Press, 2016

[7] Z. D. Yin et al., "Talent Training of information and communication engineering postgraduates by innovative achievements," presented at 2020 6th International Conference on Social Science and Higher Education (ICSSHE 2020), 2020.

[8] Y. Q. Liu, "Research on the influence of artificial intelligence on the training of accounting talents and strategy," 2021.

[9] Q. L. Luo, C. Wang, and Y. Zhao, "Cultivation strategy of college students' craftsman spirit from the perspective of artificial intelligence," Journal of Physics: Conference Series, 2020.

[10] R. Jia and P. Zhang, "Discussion on the cultivation strategy of college students' leadership in new period," The Science Education Article Collects, 2018

[11] R. Mrp et al., "Embracing disruption in engineering education," Procedia Computer Science, vol. 172, 2020, pp. 973-978.

[12] Z. Trabelsi, "Teaching network covert channels using a hands-on approach," presented at 2020 IEEE Global Engineering Education Conference (EDUCON) IEEE, 2020.

Copyright (C) 2022 by the authors. This is an open access article distributed under the Creative Commons Attribution License which permits unrestricted use, distribution, and reproduction in any medium, provided the original work is properly cited (CC BY 4.0).

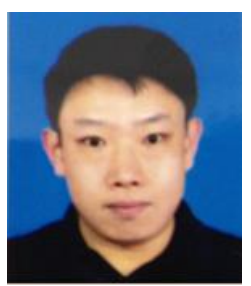

Zhendong. Yin is an associate professor of the School of Electronics Information Engineering at Harbin Institute of Technology. He received his Ph.D. degree from HIT in 2008. His current research interests are UWB wireless communication, formation flying satellites communication, and relay satellite system.

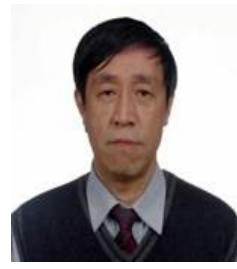

Zhilu. Wu is a professor of the School of Electronics Information Engineering at Harbin Institute of Technology. His main fields of research include space information acquisition and processing, formation flying satellite control, cognitive radio, and software radio. 


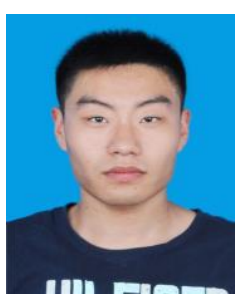

Dasen. Li was born in Heilongjiang province, China, in 1990. He is a Ph.D candidate of the School of Electronics Information Engineering at Harbin Institute of Technology. His main fields of research include image processing, computer vision, and deep learning.

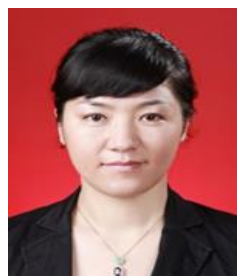

Yaqin Zhao was born in Heilongjiang province, China, in 1976. She received the B.E., M.E., and Ph.D. degrees from Harbin Institute of Technology (HIT), Harbin, China, in 1998, 2000, and 2004, respectively, in information and communication engineering. Currently, she is a professor at the School of Electronics and Information Engineering, HIT, Harbin, China. Her research interests include wireless optical communications, cognitive radio, software-defined radio, biomedical signal and image processing, and machine learning.

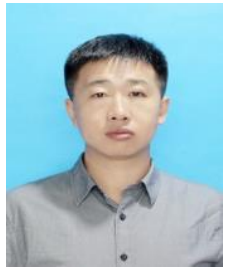

Jinlong Liu received the Ph.D. degree in 2019 from Harbin Institute of Technology, China. He is currently working as an associate professor in Harbin Institute of Technology. His current research interests include optical communication, relay satellite system and quantum cryptography. 